\title{
ИССЛЕДОВАНИЕ ЦЕЛЛЮЛОЗЫ ИЗ НЕТРАДИЦИОННОГО СЫРЬЯ И ЕЕ НИТРАТОВ МЕТОДОМ ИК-ФУРЬЕ СПЕКТРОСКОПИИ
}

\author{
А. А. Корчагина, В. В. Будаева
}

\begin{abstract}
В данной работе представлены результаты исследования нитрования технической целлюлозы, выделенной азотнокислым способом на опытном производстве из нетрадиционного ежегодно возобновляемого сырья - отходов сельскохозяйственного производства: плодовых оболочек овса и промышленной хлопковой целлюлозы. При использовании серноазотной кислотной смеси с массовой долей воды 14 \% получены образцы нитратов целлюлозы, характеризующиеся близкими фризико-химическими характеристиками: м.д. азота 11,82-12,12 \%, вязкость - 10-15 мПа·с, растворимость в спиртоэфрирной смеси - 96-98 \% и выход - 128-130\%. Установлено, что по основным свойствам экспериментальные образцы соответствуют промышленному коллоксилину «Н». При сравнении опытных иеллюлоз методом ИК-Фурье спектроскопии выявлено, что спектры исследуемых образцов содержат основные ффункциональные группы (3700-3000, 3000-2800, 1645-1640, 1400-1300, 1200-1000, 900-500 см $^{-1}$ ), которые характерны для целлюлозы. Установлено, что ИК-спектры опытных целлюлоз по основным характеристическим частотам идентичны спектрам целлюлоз из традиционного сырья: хлопка и древесины. Методом ИК-Фурье спектроскопии выявлено, что в ИК-спектрах нитратов иеллюлозы из технической целлюлозы плодовых оболочек овса и промышленной хлопковой целлюлозы содержатся полосы поглощения (2558-2556, 1662-1660, $\left.1642-1639,1279-1277,825-816,746,680 \mathrm{~cm}^{-1}\right)$, отвечающие за колебания нитрогрупп. Подтверждено, что основным полосам поглощения синтезированные образцы соответствуют промышленному коллоксилину «Н».
\end{abstract}

Ключевые слова: плодовые оболочки овса, техническая целлюлоза, нитраты целлюлозы, метод ИК-Фурье спектроскопии.

\section{ВВЕДЕНИЕ}

Целлюлоза является наиболее востребованным продуктом многоцелевого назначения и стартовой основой для получения широкого спектра новых материалов, в частности нитратов целлюлозы (НЦ). Традиционно наиболее высококачественные НЦ в производстве наиболее ответственных изделий для оборонной промышленности и гражданской продукции изготавливаются из хлопковой целлюлозы (ХЦ). Однако в последние годы качество продукции и стабильность свойств ХЦ, поставляемой в Россию из Узбекистана и Казахстана, желают оставаться лучшими. Наряду с ХЦ, используют древесную целлюлозу, производство которой сейчас приостановлено в связи с экологической вредностью, трудностью переработки и дефицитом лесных ресурсов [1].

В настоящее время актуальной проблемой является получение высококачественной целлюлозы и ее НЦ из альтернативного ежегодно возобновляемого растительного сырья взамен хлопковых и древесных целлюлоз. Одним из таких промышленно значимых ис- точников являются отходы сельскохозяйственного производства - плодовые оболочки овса (ПОО).

ИК-Фурье спектроскопия - широко известный и апробированный метод анализа, позволяющий изучать пространственное строение полимера, наличие и характер внутри- и межмолекулярных связей, определять реакционную способность данных соединений [2], массовую долю (м. д.) азота в НЦ [3] и другие характеристики. Метод ИКФурье спектроскопии чувствителен к структурным изменениям веществ. Для решения большинства структурно-аналитических задач этим методом используют диапазон частот 4000-500 $\mathrm{cm}^{-1}$. В указанных пределах содержатся полосы поглощения, соответствующие валентным колебаниям углеродного скелета ( $\left.v=3200-2700 \mathrm{~cm}^{-1}\right)$, гидроксильных групп ( $\left.v=3700-3200 \mathrm{~cm}^{-1}\right)$, нитроэфирных групп ( $\left.v=1660,1280,840 \mathrm{~cm}^{-1}\right)$, сложноэфирных групп ( $\left.v=1500-1000 \mathrm{~cm}^{-1}\right)$ и т. д.

В многочисленных работах отечественных и зарубежных ученых отражены результаты сравнения хлопковой и древесной целлюлоз с целлюлозами из альтернативного 


\section{А.А. КОРЧАГИНА, В.В. БУДАЕВА}

целлюлозосодержащего сырья, а также НЦ на его основе с промышленными НЦ.

Так, например, Г. Н. Марченко с соавторами сравнивали ИК-спектры поглощения хлопковой и древесной целлюлоз с ИКспектрами из льна, рапса, мискантуса и камыша [4]. В работе И. Н. Торгун с коллегами [1] сопоставлены ИК-спектры льняной целлюлозы с хлопковой и древесной целлюлозами, а также спектры микрокристаллических льняной, хлопковой и древесной целлюлоз. 3. Т. Валишиной с коллегами $[5,6]$ выявлено, что по структурным параметрам пеньковая целлюлоза идентична пеньковой целлюлозе зарубежного стандарта и ХЦ, кроме того в работе [5] показано, что НЦ на основе пеньковой целлюлозы характеризуется большей молекулярной однородностью в сравнении с промышленным пироксилином № 1 на основе ХЦ. В работе Ю. М. Михайлова с коллегами [2] показана эфффективность метода ИКспектроскопии для определения структурных характеристик целлюлоз различной природы (хлопковой, древесной и льняной) и НЦ на их основе. В работе Ю. А. Гисматулиной и В. В. Будаевой [7] приведено сравнение целлюлоз, выделенных из мискантуса, листа и стебля отдельно, двумя способами: азотнокислым и комбинированным с ХЦ. Установлено, что ИК-спектры опытных целлюлоз по основным характеристическим частотам совпадают со спектром промышленной ХЦ. В последние годы в качестве перспективного источника целлюлозы и НЦ исследователями рассматривается мискантус, о чем свидетельствуют работы [8-12]. D. Trache с коллегами показана принципиальная возможность получения НЦ на основе травы эспарто [13] и выявлено, что по основным характеристическим частотам полимеры соответствуют НЦ.

Однако, несмотря на большое количество публикаций по получению целлюлозы и ее нитратов из альтернативного растительного сырья, сведения об исследовании целлюлозы из ПОО и НЦ на ее основе методом ИКФурье спектроскопии отсутствуют.

Целью данной работы являлось получение НЦ на основе технической целлюлозы (ТЦ) из ПОО и ХЦ, а также сравнение опытных целлюлоз и НЦ методом ИК-Фурье спектроскопии с промышленными образцами.

\section{ЭКСПЕРИМЕНТАЛЬНАЯ ЧАСТЬ}

Объектами исследования являлись: ТЦ, выделенная из ПОО на опытном производстве ИПХЭТ СО РАН азотнокислым способом (таблица 1), включающим в себя последова- тельную обработку исходного сырья разбавленными растворами азотной кислоты и гидроксида натрия при атмосферном давлении и температуре около 90-95 ${ }^{\circ} \mathrm{C}[8,14]$ и промышленная ХЦ (таблица 1), предоставленная с Бийского химического комбината. Образцы НЦ получали путем обработки целлюлоз серно-азотной кислотной смесью (КС), используемой в промышленности при изготовлении нитроэфиров [15] в условиях синтеза коллоксилина «Н» с м. д. воды в КС 14 \% при температуре $30{ }^{\circ} \mathrm{C}$ в течение 40 мин, модуль нитрования 1:25 [9, 16, 17]. Далее образцы НЦ стабилизировали по схеме: обработка в воде в течение 1 ч при температуре $85-95^{\circ} \mathrm{C}$ (требуемого уровня кислотности достигали за счет остаточного количества кислот в НЦ), высокотемпературная обработка в автоклаве в 0,3\%-ном растворе азотной кислоты в течение 60-130 мин при $130{ }^{\circ} \mathrm{C}$, обработка в 0,03\%-ном растворе карбоната натрия в течение 3 ч при температуре $85-95^{\circ} \mathrm{C}$, повторная обработка в воде в течение 1 ч при температуре $85-95^{\circ} \mathrm{C}$ и окончательная промывка образцов до нейтральной реакции промывных вод.

Основные фризико-химические характеристики образцов НЦ были определены по стандартным методикам, действующим в отрасли, м. д. азота определяли ферросульфатным способом [3].

ИК-спектры образцов целлюлоз и НЦ регистрировали на спектрометре «Инфралюм801» (Россия) в диапазоне частот 4000$500 \mathrm{~cm}^{-1}$. Для съемки спектров прессовали таблетки в соотношении $\mathrm{HЦ}: \mathrm{KBr}=1: 150$.

Работа была выполнена при использовании оборудования Бийского регионального центра коллективного пользования СО РАН (ИПХЭТ СО РАН, г. Бийск).

\section{РЕЗУЛЬТАТЫ И ОБСУЖДЕНИЕ}

При выборе целлюлозного сырья для нитрования решающее значение имеет не только химическая чистота целлюлозного материала, т. е. содержание в нем нецеллюлозных компонентов, но и структура волокна [1]. При изготовлении коллоксилина «Н» рекомендуют использовать целлюлозы с м. д. а-целлюлозы не менее 92 \% и суммарным количеством нецеллюлозных компонентов не более 1,2 \% [1]. Используемый в оборонной промышленности коллоксилин «Н», должен удовлетворять следующим требованиям: м. д. азота - 11,85-12,29 \%, вязкость - 8,515,8 мПа.с, растворимость в спиртоэфирной смеси - не менее $98 \%$ [18, 19].

ПОЛЗУНОВСКИЙ ВЕСТНИК № 22018 


\section{ИССЛЕДОВАНИЕ ЦЕЛЛЮЛОЗЫ ИЗ НЕТРАДИЦИОННОГО СЫРЬЯ И ЕЕ НИТРАТОВ МЕТОДОМ ИК-ФУРЬЕ СПЕКТРОСКОПИИ}

Из представленных в таблице 1 данных следует, что ТЦ, выделенная из ПОО азотнокислым способом на опытном производстве ИПХЭТ СО РАН (таблица 1), характеризуется высокой м. д. а-целлюлозы - 94 \% - с одновременно высокой суммарной м. д. нецеллюлозных компонентов - 3,77 \% - по сравнению с промышленной ХЦ, у которой м. д. $\alpha-$ целлюлозы составляет 97 \%, а суммарное количество нецеллюлозных компонентов 0,85 \%. ТЦ из ПОО, в сравнении с ХЦ, имеет высокую СП - 1390 против 1080. Смачиваемость ТЦ из ПОО на 18 г ниже, чем у ХЦ, что может быть обусловлено морфологическими особенностями исходного сырья.

Таблица 1 - Физико-химические характеристики ТЦ, выделенной из ПОО азотнокислым способом на опытном производстве ИПХЭТ СО РАН, и промышленной ХЦ

\begin{tabular}{|c|c|c|c|c|c|c|}
\hline \multirow[b]{2}{*}{$\begin{array}{c}\text { Наименование } \\
\text { образца }\end{array}$} & \multicolumn{4}{|c|}{ Массовая доля*, \% } & \multirow[b]{2}{*}{ СП } & \multirow{2}{*}{$\begin{array}{c}\text { Смачи- } \\
\text { ваемость, } \\
\text { г }\end{array}$} \\
\hline & $\begin{array}{c}\alpha- \\
\text { целлюлозы }\end{array}$ & $\begin{array}{c}\text { остаточного } \\
\text { лигнина }\end{array}$ & золы & пентозанов & & \\
\hline ТЦ из ПОО & $94,0 \pm 0,5$ & $0,48 \pm 0,05$ & $0,39 \pm 0,05$ & 2,9 & 1390 & 112 \\
\hline ХЦ & $97,0 \pm 0,5$ & $0,20 \pm 0,05$ & $0,15 \pm 0,05$ & $0,5 \pm 0,05$ & 1080 & 130 \\
\hline
\end{tabular}

Примечание: * - определено по стандартным методикам [20] в пересчете на абсолютно сухое сырье; СП - степень полимеризации.

В таблице 2 приведены свойства образцов НЦ из ТЦ ПОО и ХЦ в сравнении с промышленным коллоксилином «Н».

Согласно данным, представленным в таблице 2, образцы НЦ, полученные из ТЦ ПОО и ХЦ, характеризуются близкими фризи- ко-химическими характеристиками: м. д. азота - 11,82-12,12 \%, вязкость - 10-15 мПа·с, растворимость в спиртоэфирной смеси - 96$98 \%$, выход - 128-130\%. Установлено, что по основным показателям НЦ соответствуют промышленному коллоксилину «Н» $[18,19]$.

Таблица 2 - Физико-химические характеристики НЦ из ТЦ ПОО и ХЦ в сравнении промышленным коллоксилином «Н» $[18,19]$

\begin{tabular}{|c|c|c|c|c|}
\hline \multirow{2}{*}{$\begin{array}{c}\text { Наименование } \\
\text { образца }\end{array}$} & $\begin{array}{c}\text { м.д. } \\
\text { азота, \% }\end{array}$ & $\begin{array}{c}\text { вязкость 2\%-го } \\
\text { раствора } \\
\text { в ацетоне, мПа·с }\end{array}$ & $\begin{array}{c}\text { растворимость в } \\
\text { спиртоэфирной } \\
\text { смеси, \% }\end{array}$ & Выход, \% \\
\hline НЦ из ТЦ ПОО & $12,12 \pm 0,05$ & $10 \pm 1$ & $98 \pm 2$ & 130 \\
\hline НЦ из ХЦ & $11,82 \pm 0,05$ & $15 \pm 1$ & $96 \pm 2$ & 128 \\
\hline $\begin{array}{c}\text { Промышленный } \\
\text { коллоксилин «Н» }[18]\end{array}$ & $11,85-12,29$ & $8,5-15,8$ & не менее 98 & $\sim 142$ \\
\hline
\end{tabular}

Для получения информации о молекулярной структуре образцов исходных целлюлоз и НЦ были проведены исследования с помощью ИК-Фурье спектроскопии в области частот 4000-500 $\mathrm{cm}^{-1}$.

На рисунке 1 приведены ИК-спектры ТЦ из ПОО (рисунок 1 а) и промышленной ХЦ (рисунок 1, б). В ИК-спектрах исследуемых образцов целлюлоз наблюдается интенсивная широкая полоса поглощения сложной формы в области валентных колебаний гидроксильных (OH-) групп при 3600-3200 $\mathrm{cm}^{-1}$, включенных в водородную связь, и менее интенсивная полоса поглощения валентных колебаний $-\mathrm{CH}-,-\mathrm{CH}_{2}$ в области 3000$2800 \mathrm{~cm}^{-1}$ воды [21]. Интенсивная полоса с максимумом около $1640 \mathrm{~cm}^{-1}$ принадлежит деформационным колебаниям ОН-групп воды, присутствующей в целлюлозах. При увеличении содержания воды максимум не- сколько смещается в сторону больших волновых чисел. Установлено, что область частот 1500-1400 см-1 в ИК-спектрах углеводов чувствительна к изменению конфрормаций оксиметильной группы. Относительно четко выделяющаяся полоса около $1433 \mathrm{~cm}^{-1}$ связана с внутренними деформационными колебаниями $\mathrm{CH}_{2}$ в группах $\mathrm{CH}_{2} \mathrm{OH}$. В области 1400-1300 см ${ }^{-1}$ в ИК-спектрах целлюлоз лежат частоты деформационных колебаний групп $\mathrm{C}-\mathrm{OH}, \mathrm{CH}$. Полосы поглощения около 1370-1360, $1320 \mathrm{~cm}^{-1}$ отнесены за счет первичных гидроксильных групп различных поворотных изомеров. Полосы поглощения в области 1200-1000 см-1 обусловлены в основном валентными колебаниями С-О. Полосы в интервале частот 900-700 $\mathrm{cm}^{-1}$ могут быть обусловлены маятниковыми колебаниями метиленовых групп, дефооммационными колебаниями связей СН и пиранозных звень- 
ев. Размытое поглощение с нечетко выраженной структурой в области 700-400 см-1 можно отнести за счет деформационных колебаний гидроксильных групп и обертонов водородных связей [21].

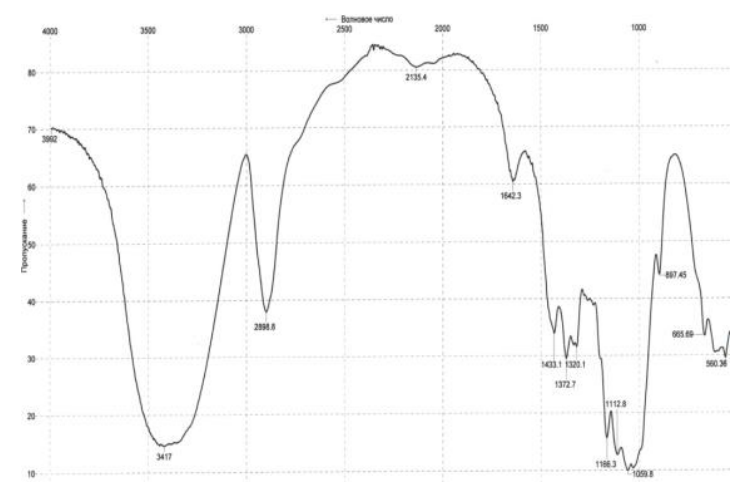

a

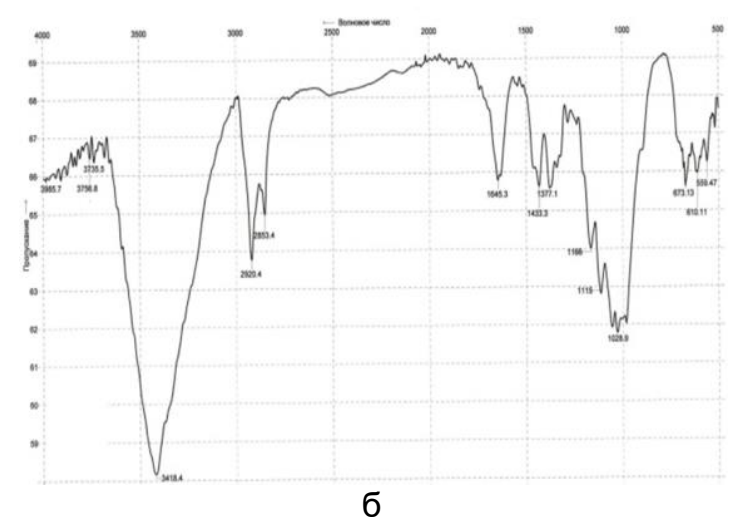

Рисунок 1 - ИК-спектры: а) ТЦ из ПОО;

б) промышленной ХЦ

Таким образом, ИК-спектры образцов исследуемых целлюлоз по основным полосам поглощения идентичны спектрам образцов целлюлозы, полученных из традиционных видов сырья (хлопок и древесина) [2, 18, 21, 22.]

В таблице 3 приведено отнесение полос в ИК-спектрах НЦ из ТЦ ПОО, ХЦ и промышленного коллоксилина «Н». Во всех спектрах, синтезированных образцов НЦ зарегистрированы характеристические частоты, свидетельствующие о структурных особенностях макромолекул НЦ. Из таблицы 3 следует, что в спектрах НЦ в области 37003200 см$^{-1}$ присутствуют пики валентных колебаний $v(\mathrm{OH})$ в виде широкой полосы сложного контура, что свидетельствует о неполном замещении НЦ. Они принадлежат гидроксильным группам НЦ, участвующим в образовании водородных связей, и являются характерным признаком химической неоднородности НЦ. Полоса поглощения около
2925-2922 см-1 отвечает за валентные колебания $\mathrm{CH}$-групп. Валентные колебания нитратных групп соответствует полосе поглощения около 2558-2556 см-1.

Таблица 3 - Отнесение полос в ИКспектрах НЦ из ТЦ ПОО, ХЦ и промышленного коллоксилина «Н»

\begin{tabular}{|c|c|c|c|}
\hline \multirow{3}{*}{$\begin{array}{c}\text { Отнесение } \\
\text { к химическим } \\
\text { группам }\end{array}$} & \multicolumn{3}{|c|}{$\begin{array}{c}\text { Наименование } \\
\text { образца }\end{array}$} \\
\hline & $\begin{array}{c}\text { НЦ } \\
\text { из ТЦ } \\
\text { ПОО }\end{array}$ & $\begin{array}{l}\text { НЦ } \\
\text { из } \\
\text { ХЦ }\end{array}$ & $\begin{array}{c}\text { Кол- } \\
\text { локси } \\
\text { лин } \\
\text { «Н» }\end{array}$ \\
\hline & \multicolumn{3}{|c|}{ Частота, см $^{-1}$} \\
\hline $\begin{array}{l}\text { Валентные } \\
\text { колебания } \\
\mathrm{v}(\mathrm{OH})(\mathrm{OH} . . . \mathrm{OH})\end{array}$ & 3568 & 3563 & 3468 \\
\hline $\begin{array}{l}\text { Валентные } \\
\left.\text { колебания v( } \mathrm{CH}_{2}\right)\end{array}$ & 2922 & 2924 & 2925 \\
\hline $\begin{array}{l}\text { Валентные } \\
\text { колебания 2v(NO} 2)\end{array}$ & 2558 & 2556 & 2556 \\
\hline $\begin{array}{l}\text { Валентные } \\
\text { колебания } \mathrm{va}_{2}\left(\mathrm{NO}_{2}\right)\end{array}$ & 1660 & 1662 & 1660 \\
\hline $\begin{array}{l}\text { Дефрормационные } \\
\text { колебания } \sigma\left(\mathrm{CH}_{2}\right)\end{array}$ & 1639 & 1640 & 1642 \\
\hline $\begin{array}{l}\text { Дефрормационные } \\
\text { колебания } \sigma(\mathrm{COH})\end{array}$ & 1428 & 1432 & 1436 \\
\hline $\begin{array}{l}\text { Деформационные } \\
\text { колебания } \sigma(\mathrm{CH})\end{array}$ & 1379 & 1379 & 1387 \\
\hline $\begin{array}{l}\text { Симметричные } \\
\text { валентности } \\
\mathrm{v}_{\mathrm{s}}\left(\mathrm{NO}_{2}\right)\end{array}$ & 1277 & 1277 & 1279 \\
\hline $\begin{array}{l}\text { Валентные } \\
\text { колебания v(C-O) }\end{array}$ & 1164 & 1165 & 1166 \\
\hline $\begin{array}{l}\text { Валентные } \\
\text { колебания v(C-O) }\end{array}$ & 1072 & 1072 & 1072 \\
\hline $\begin{array}{l}\text { Деформационные } \\
\text { колебания } \sigma(\mathrm{CH})\end{array}$ & 1000 & 1001 & 1001 \\
\hline $\begin{array}{l}\text { Валентное } \\
\text { колебание v(NO} 2)\end{array}$ & 825 & 823 & 816 \\
\hline $\begin{array}{l}\text { Веерное } \\
\text { колебание } \mathrm{\gamma w}\left(\mathrm{NO}_{2}\right)\end{array}$ & 747 & 746 & 746 \\
\hline $\begin{array}{l}\text { Ножничное } \\
\text { колебание } \delta\left(\mathrm{NO}_{2}\right)\end{array}$ & 681 & 681 & 680 \\
\hline
\end{tabular}

В ИК-спектрах образцов НЦ в области 1700-1500 см-1 перекрываются несколько полос. По литературным данным [22], полоса в области около 1662-1660 см-10тнесена к va $\left(\mathrm{NO}_{2}\right)$ нитратных групп, связанных с СН-группами глюкопиранозных циклов НЦ (положение $\mathrm{C}_{(2)}$ и/или $\mathrm{C}_{(3)}$ ), интенсивная полоса в области 1642-1639 см-1 отвечает за колебания $\mathrm{va}_{\mathrm{a}}\left(\mathrm{NO}_{2}\right)$ нитратных групп, связанных с $\mathrm{CH}_{2}$-группами глюкопиранозных циклов НЦ (положение $\left.\mathrm{C}_{(6)}\right)$. Это хорошо согласуется с данными по отнесению полосы $\mathrm{va}\left(\mathrm{NO}_{2}\right)$ 


\section{ИССЛЕДОВАНИЕ ЦЕЛЛЮЛОЗЫ ИЗ НЕТРАДИЦИОННОГО СЫРЬЯ И ЕЕ НИТРАТОВ МЕТОДОМ ИК-ФУРЬЕ СПЕКТРОСКОПИИ}

нитратов первичных и вторичных спиртов. Известно, что замещение $\mathrm{H}$ - группы на $\mathrm{NO}_{2}-$ преимущественно происходит в положении $\mathrm{C}_{(6)}$ и в неравной степени в положениях $\mathrm{C}_{(2)}$ и $\mathrm{C}_{(3)}$ в зависимости от степени этерификации.

Полоса поглощения при 1436-1428 см-1 относится к ножничному колебанию $\mathrm{CH}_{2}-$ групп. В ИК-спектрах образцов НЦ в области 1200-1500 $\mathrm{CM}^{-1}$ имеются полосы поглощения около 1387$1379 \mathrm{~cm}^{-1}$ и 1279-1277 см-1, интенсивность которых заметно снижается при уменьшении м.д. азота [21]. Полоса при 1387-1379 $\mathrm{cm}^{-1}$ может быть отнесена к деформационным колебаниям CH-групп, а интенсивная полоса поглощения при 1279-1277 см $^{-1}$ соответствует симметричными валентными колебаниями групп $\mathrm{NO}_{2}$. Полоса поглощения при 1166-1164 см-1 характеризуется валентными колебаниями гликозидной связи. Полоса поглощения около $1072 \mathrm{~cm}^{-1}$ обусловлена валентными колебаниями связей С-О, соединяющих пиранозные циклы, а полоса при 1000 $\mathrm{cm}^{-1}$ обусловлена деформационными колебаниями СН-групп. В спектрах образцов НЦ проявляется ряд полос, обусловленных поглощением

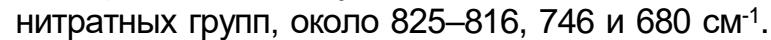
Эти полосы относятся соответственно к валентным колебаниям N-O, внеплоскостным маятниковым колебаниям $\mathrm{NO}_{2}$ и к плоскостным деформационным колебаниям $\mathrm{NO}_{2}[2,21,22]$. В ИКспектре НЦ из ТЦ ПОО наблюдается незначительные смещения характеристических частот в длинноволновую область, в сравнении со спектром промышленного НЦ, что может быть обусловлено ослаблением межмолекулярных связей. Сравнение полученных ИК-спектров образцов НЦ из ТЦ ПОО и ХЦ, со спектром промышленного коллоксилина «Н» свидетельствует о структурном сходстве данных полимеров [25, 26].

\section{выводы}

В результате обработки ТЦ из ПОО и промышленной ХЦ серно-азотной КС с м.д. воды 14 \% получены образцы НЦ с близкими фризико-химическими характеристиками: м.д. азота - 11,82-12,12 \%, вязкость - 1015 мПа.с, растворимость в спиртоэфирной смеси - 96-98 \%, выход - 128-130 \%. Установлено, что по основным показателям синтезированные НЦ соответствуют промышленному коллоксилину «Н». При сравнении ТЦ из ПОО и промышленной ХЦ методом ИК-Фурье спектроскопии выявлено, что в спектрах исследуемых образцов содержатся основные функциональные группы (3700-3000, 30002800, 1645-1640, 1400-1300, 1200-1000, 900$\left.500 \mathrm{~cm}^{-1}\right)$, характерные для целлюлозы. Установлено, что ИК-спектры опытных целлюлоз по основным характеристическим частотам идентичны спектрам целлюлоз из хлопка и древесины. Методом ИК-Фурье спектроскопии выявлено, что НЦ на основе ТЦ из ПОО и ХЦ содержат полосы поглощения (2558-2556, 1662-1660, 1642-1639, 1279-1277, 825-816, $\left.746,680 \mathrm{~cm}^{-1}\right)$, отвечающие за колебания нитрогрупп и позволяющие идентифицировать полученные продукты как азотнокислые эфиры целлюлозы. Также установлено, что основным полосам поглощения образцы НЦ соответствуют промышленному коллоксилину «Н».

Работа выполнена при поддержке программы фрундаментальных исследований президиума РАН № 56 «Фундаментальные основы прорывных технологий в интересах национальной безопасности» (проект № 0385-2018-0015).

\section{СПИСОК ЛИТЕРАТУРЫ}

1. Лен в пороховой промышленности. Научное издание, доп. и перер. / под. ред. С. И. Григорова. - М. : ФГУП «ЦНИИХМ», 2015. - 348 с.

2. Спектральное исследование целлюлозы и нитратов целлюлозы / Ю. М. Михайлов, Н. А. Романько, Р. Ф. Гатина [и др.] // Боеприпасы и высокоэнергетические конденсированные системы. 2010. - № 1. - С. 52-62.

3. Геньш, К. В. Количественный анализ нитратов целлюлозы методом ИК-Фурьеспектроскопии / К. В. Геньш, П. В. Колосов, Н. Г. Базарнова // Химия растительного сырья. - 2010. № 1. - C. 63-66.

4. Марченко, Г. Н. Структурно-химические свойства целлюлозы и ее аналогов. Новые источники сырья, методы их переработки / Г. Н. Марченко, О. К. Нугманов, Р. И. Шакиров, Р. Я. Дербердеев. - Казань : «Печать-Сервис XXI век», 2017. 293 c.

5. Валишина, 3. Т. Исследование структуры целлюлозы из пенькового волокна и нитрата целлюлозы на ее основе / 3. Т. Валишина, Г. Н. Галиуллина, Е. С. Петров, Н. И. Наумкина, А. В. Косточко // Вестник технологического университета. -2015. - Т. 18, № 13. - С. 149-152.

6. Исследование свойств азотнокислых эфиров целлюлозы на основе пеньковой целлюлозы / 3. Т. Валишина, А. В. Иванова, Б. Ф. Мухаметшин, А. А. Александров, А. В. Косточко // Вестник технологического университета. - 2016. - Т. 19, № 18. C. $65-68$.

7. Гисматулина, Ю. А. Сравнение целлюлоз, выделенных из мискантуса, с хлопковой целлюлозой методом ИК-Фурье спектроскопии / Ю. А. Гисматулина, В. В. Будаева // Ползуновский вестник. - 2014. - № 3. - С. 177-181.

8. Gismatulina, Yu. A. Nitrocellulose Synthesis from Miscanthus Cellulose / Yu. A. Gismatulina, V. V. Budaeva, G. V. Sakovich // Propellants, Explosives, Pyrotechnics. - 2018. - Vol. 43. - P. 96-100. 


\section{А.А. КОРЧАГИНА, В.В. БУДАЕВА}

9. Корчагина, А. А. Оптимальные условия синтеза коллоксилина «Н» из мискантуса / А. А. Корчагина, Ю. А. Гисматулина, А. А. Кухленко // Ползуновский вестник. - 2017. - № 3. - С. 107-114.

10. Нугманов, О. К. Структурный анализ травяной целлюлозы / О. К. Нугманов, Н. П. Григорьева, Н. А. Лебедев // Химия растительного сырья. 2013. - № 1. - С. 29-37.

11. Шипина, О. Т. ИК-спектроскопические исследования целлюлозы из травянистых растений /

О. Т. Шипина, М. Р. Гараева, А. А. Александров // Вестник Казанского технологического университета. - 2009. - № 6. - С. 148-152.

12. Денисова, М. Н. Исследование структур мискантуса, гидротропной целлюлозы и нитратов, полученных из нее / М. Н. Денисова, А. Г. Огиенко, В. В. Будаева // Химия растительного сырья. -2012. - № 4. - C. 19-27.

13. Physicochemical properties of microcrystalline nitrocellulose from alfa grass fibres and its thermal stability / D. Trache, K. Khimeche, A. Mezroua, M. Benziane // Therm Anal Calorim. - 2016. - Vol. 124 (3). - P. 1485-1496.

14. Gismatulina, Yu. A. Cellulose nitrates from intermediate flax straw / Yu. A. Gismatulina, V. V. Budaeva, G. V. Sakovich // Russian Chemical Bulletin. - 2016. - Vol. 65, No. 12. - P. 2920-2924.

15. Питеркин, Р. Н. Технология нитроэфиров и нитроэфирсодержащих промышленных взрывчатых веществ / Р. Н. Питеркин, Р. Ш. Просвирнин, Е. А. Петров // Монография. - Бийск: Изд-во АлтГТУ им. И.И. Ползунова, 2012. - 268 с.

16. Корчагина, А. А. К вопросу технологии нитрования целлюлозы из альтернативного сырья / А. А. Корчагина // Фундаментальные исследования. - 2017. - № 2.- С. 62-68.

17. Якушева, А. А. Нитраты целлюлозы из нового источника целлюлозы - плодовых оболочек овса / А. А. Якушева // Фундаментальные исследования. - 2014. - № 8. - Ч. 2. - С. 360-364.
18. Новый справочник химика и технолога. Сырье и продукты промышленности органических и неорганических веществ / Ч. II; под ред. В. А. Столяровой. - СПб.: НПО «Профрессионал», 2006. -916 C.

19. Энергетические конденсированные системы. Краткий энциклопедический словарь / Под ред. Б. П. Жукова. Изд. 2-е, исправл. - М.: «ЯнусК», 2000. - 296 c.

20. Оболенская, А. В. Лабораторные работы по химии древесины и целлюлозы / А. В. Оболенская, 3. П. Ельницкая, А. А. Леонович. - М.: Экология, 1991. -320 с.

21. Жбанков, Р. Г. Инфракрасные спектры и структура углеводов / Р. Г. Жбанков. - Минск: Наука и техника, 1972. - 456 с.

22. Коваленко, В. И. Структурно-кинетические особенности получения и термодеструкции нитратов целлюлозы / В. И. Коваленко, Г. М. Сопин, Г. М. Храпковский / Ин-т орган. и физ. химии им. А.Е. Арбузова. - Минск. Наука, 2005. - 213 с.

Корчагина Анна Александровна, к.т.н, младший научный сотрудник лаборатории биоконверсии, ФГБУН «Институт проблем химико-энергетических технологий» Сибирского отделения Российской академии наук (ИПХЭТ СО РАН), e-mail: Yakusheva89_21.ru@mail.ru, тел.: (3854) 3059-85.

Будаева Вера Владимировна, к.Х.н., доцент, заведующая лабораторией биоконверсии, ФГБУН «Институт проблем химикоэнергетических технологий» Сибирского отделения Российской академии наук (ИПХЭТ СО РАН), e-mail: budaeva@ipcet.ru, тел.: (3854) 30-59-85. 